\title{
Selective Propargylation of Diaryl Azo Compounds Using Metallic Barium
}

\author{
Akira Yanagisawa* \\ Toshihiko Heima \\ Kana Watanabe \\ Shun Haeno
}

Soft Molecular Activation Research Center, Molecular Chirality Research Center, Department of Chemistry, Graduate School of Science, Chiba University, Inage, Chiba 263-8522, Japan ayanagi@faculty.chiba-u.jp

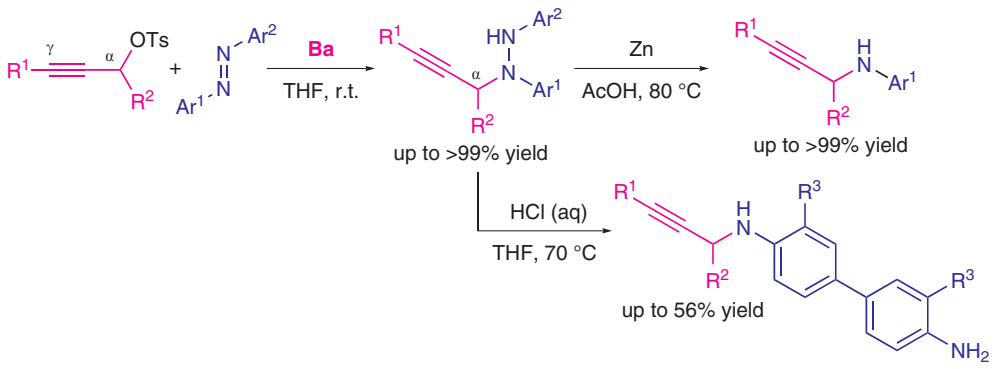

Received: 17.06.2020

Accepted after revision: 13.07.2020

Published online: 17.08 .2020

DOI: 10.1055/s-0040-1706414; Art ID: st-2020-u353-I

Abstract The Barbier-type propargylation of azo compounds with $\alpha, \gamma$ disubstituted propargylic tosylates was achieved by using metallic barium as the promoter. Various propargylated hydrazines ( $\alpha$-adducts) were exclusively synthesized from the corresponding propargylic tosylates and azobenzenes (diaryldiazenes). The thus-obtained propargylic hydrazines were further efficiently converted into propargylic amines by reductive $\mathrm{N}-\mathrm{N}$ bond cleavage. Benzidine rearrangement of the propargylic hydrazines was also attempted.

Key words azo compounds, barium, hydrazines, propargylation, propargylic tosylates

Propargylic/allenylic barium compounds, which are generated from Rieke barium ${ }^{1}$ and propargylic halides, are useful reagents for the synthesis of organic molecules having a carbon-carbon triple bond and high $\alpha$-regioselectivity. ${ }^{2}$ We have previously reported that a propargylation of azo compounds with propargylic halides occurs via a Barbier-type procedure using reactive barium as the low-valent metal to yield propargylic hydrazines ( $\alpha$-product). ${ }^{3}$ In addition, a Grignard-type $\alpha$-allylation of azo compounds with allylic barium reagents ${ }^{4}$ and a Barbier-type benzylation of azo compounds with benzylic chlorides ${ }^{5}$ have been achieved. We report herein a metallic-barium-promoted Barbier-type propargylation of azo compounds with propargylic tosylates (Scheme 1). The results of reductive N-N bond cleavage of the products, propargylic hydrazines, to form the corresponding propargylic amines as well as benzidine rearrangement of the propargylic hydrazines are also disclosed. The propargylic amine structure is often seen as a key framework in pharmaceutical compounds, such as rasagiline mesylate ${ }^{6}$ and selegiline hydrochloride. ${ }^{7}$ Therefore, the development of useful methods for the synthesis

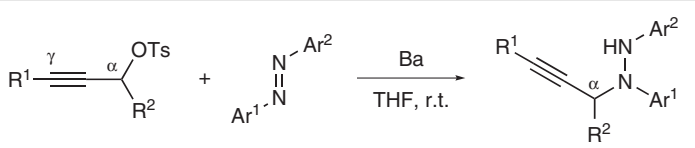

Scheme 1 Barbier-type propargylation of azobenzenes using metallic barium

of such propargylic amines has captivated the interest of researchers in the field of organic synthesis.

We have found that allylic barium reagents can be prepared from metallic barium and allylic chlorides and show high reactivity toward isatin imines with $\alpha$-selectivity. ${ }^{8} \mathrm{We}$ envisioned that if a propargylic or an allenylic barium reagent could be generated from metallic barium ${ }^{9}$ and the corresponding propargylic halide under mild reaction conditions and displayed $\alpha$-selectivity in the reaction with an azo compound, the propargylation would provide a practical synthetic procedure for propargylated hydrazines. Thus, we first selected (3-chloroprop-1-ynyl)trimethylsilane (1a) and azobenzene (2a) as the precursor of propargylic or allenylic barium reagent and the electrophile, respectively, and attempted to perform a Barbier-type reaction due to the simplicity of the experimental procedure. When a 3:1 mixture of propargylic chloride 1a (3 equiv) and azobenzene (2a, 1 equiv) was treated with metallic barium (3 equiv) in THF at room temperature for $14 \mathrm{~h}$, the reaction did not proceed and targeted propargylated hydrazine 3aa $(\alpha-$ adduct) was not observed at all (Table 1 , entry 1 ). In contrast, $\alpha$-methylated trimethylsilyl-substituted propargylic chloride $\mathbf{1 b}$ showed remarkable reactivity toward $\mathbf{2 a}$ and the desired product was obtained in $49 \%$ yield without formation of the corresponding allenylated hydrazine under similar reaction conditions (entry 2). However, the reaction of $\alpha$-dimethylated propargylic chloride $\mathbf{1 c}$ with $\mathbf{2 a}$ resulted in a low yield (entry 3 ). $\alpha$-Methylated tert-butyl-substituted 
Table 1 Optimization of Metallic-Barium-Promoted Barbier-Type Propargylation of Azobenzene (2a) ${ }^{\mathrm{a}}$

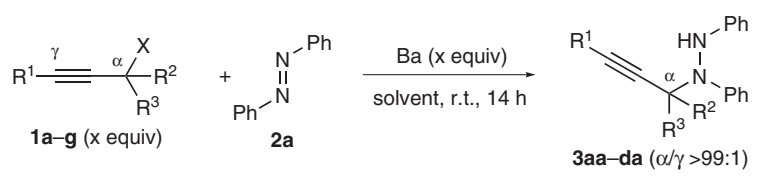

\begin{tabular}{|c|c|c|c|c|c|c|c|c|}
\hline Entry & $\mathrm{R}^{1}$ & $\mathrm{R}^{2}$ & $\mathrm{R}^{3}$ & $x$ & $\mathrm{x}$ & Solvent & Product & Yield (\%) \\
\hline 1 & $\mathrm{Me}_{3} \mathrm{Si}$ & $\mathrm{H}$ & $\mathrm{H}$ & $\mathrm{Cl} \mathbf{1 a}$ & 3 & THF & 3aa & $<1$ \\
\hline 2 & $\mathrm{Me}_{3} \mathrm{Si}$ & Me & $\mathrm{H}$ & $\mathrm{Cl} \mathbf{1 b}$ & 3 & THF & 3 ba & 49 \\
\hline 3 & $\mathrm{Me}_{3} \mathrm{Si}$ & Me & $\mathrm{Me}$ & $\mathrm{Cl} \mathbf{1 c}$ & 3 & THF & $3 c a$ & 23 \\
\hline 4 & $t$-Bu & Me & $\mathrm{H}$ & $\mathrm{Cl} \mathbf{1 d}$ & 3 & THF & 3da & 46 \\
\hline 5 & $t$-Bu & Me & $\mathrm{H}$ & $\mathrm{Cl} \mathbf{1 d}$ & 3 & DMF & 3da & 38 \\
\hline 6 & $t$-Bu & Me & $\mathrm{H}$ & $\mathrm{Cl} \mathbf{1 d}$ & 3 & THF-DMF (4:1) & 3da & 60 \\
\hline 7 & $t$-Bu & Me & $\mathrm{H}$ & OTs 1 e & 3 & THF-DMF $(4: 1)$ & 3da & 72 \\
\hline 8 & $t$-Bu & Me & $\mathrm{H}$ & $\mathrm{OPO}(\mathrm{OPh})_{2} \mathbf{1 f}$ & 3 & THF-DMF $(4: 1)$ & 3da & 46 \\
\hline 9 & $t-B u$ & Me & $\mathrm{H}$ & $\mathrm{OCOCF}_{3} \mathbf{1 g}$ & 3 & THF-DMF $(4: 1)$ & 3da & $<1$ \\
\hline 10 & $t$-Bu & Me & $\mathrm{H}$ & OTs 1 e & 2 & THF-DMF $(4: 1)$ & 3da & 47 \\
\hline 11 & $t$-Bu & Me & $\mathrm{H}$ & OTs 1 e & 4 & THF-DMF $(4: 1)$ & 3da & 47 \\
\hline 12 & $t$-Bu & Me & $\mathrm{H}$ & OTs 1e & 3 & THF & 3da & 69 \\
\hline
\end{tabular}

a The Barbier-type reaction was carried out using propargylic compounds $\mathbf{1} \mathbf{a}-\mathbf{g}$ (x equiv), metallic barium (x equiv), and azobenzene ( 2 a, 1 equiv) in the specified solvent at room temperature for $14 \mathrm{~h}$.

b The chemical yield was determined by ${ }^{1} \mathrm{H}$ NMR spectroscopy using 1,4-bis(trimethylsilyl)benzene as the internal standard.

propargylic chloride 1d showed similar reactivity toward 1b and target adduct 3da was formed in 46\% yield (entry 4 ). Subsequently, we examined solvent effect (entries 4-6) and found that a 4:1 mixture of THF and DMF was the most suitable solvent from the point of view of chemical yield (entry 6). We further focused on electron-withdrawing group $\mathrm{X}$ of substrate $\mathbf{1}$ and when propargylic tosylate 1e was employed, the highest chemical yield (72\%) was attained (entry 7). Diphenyl phosphate was also a promising $X$ group (entry 8); in contrast, trifluoroacetate gave unsatisfactory results and desired adduct 3da was not obtained in the reaction (entry 9). The chemical yield of 3da shown in entry 7 was not improved when the amounts of propargylic tosylate 1e and metallic barium were decreased or increased (entries 10 and 11). THF was also a suitable solvent in the reaction of 1e, and 69\% yield of product 3da was obtained under the optimized reaction conditions (entry 12).

With the optimum reaction conditions in hand, we examined the propargylation of azobenzene (2a) with propargylic tosylates $\mathbf{1 e}$ and $\mathbf{1 h}-\mathbf{m}$ derived from various propargylic alcohols (Table 2). Higher reactivity was observed for the reaction of propargylic tosylate $\mathbf{1 h}$, which has an ethyl group as the $\mathrm{R}^{2}$ group (entry 2 ). In contrast, propargylic tosylate 1i, which has an isopropyl group, afforded product 3fa in a lower yield than propargylic tosylate 1e probably due to its steric hindrance (entry 3 vs. entry 1). Employment of phenyl-substituted propargylic tosylate $\mathbf{1 k}$ caused a significant decrease in the yield (31\%) of its product 3ha (entry 5). Trialkylsilyl-substituted propargylic tosylates $\mathbf{1 1}$ and $\mathbf{1 m}$ furnished products in satisfactory yields (entries 6 and 7).

We performed the metallic-barium-promoted Barbiertype propargylation of symmetrical azobenzenes $\mathbf{2 b - k}$ derived from a diversely substituted aniline (Table 3 ). The ef-

Table 2 Metallic-Barium-Promoted Barbier-Type Propargylation of Azobenzene (2a) with Various Propargylic Tosylates $\mathbf{1 e}$ and $\mathbf{1} \mathbf{h}-\mathbf{m}^{\mathrm{a}}$

\begin{tabular}{|c|c|c|c|c|}
\hline \multicolumn{2}{|c|}{$\mathrm{R}^{1} \stackrel{\gamma}{=} \underbrace{\mathrm{OTs}}_{\mathbf{1}, \mathbf{h}-\mathbf{m} \text { (3 equiv) }}$} & $\frac{\mathrm{Ba}(3 \mathrm{e}}{\mathrm{THF}, \text { r.t. }}$ & \multicolumn{2}{|c|}{ 3ba, 3da, 3ea-ia $(\alpha / \gamma>99: 1)$} \\
\hline Entry & $\mathrm{R}^{1}$ & $\mathrm{R}^{2}$ & Product & Yield (\%) \\
\hline 1 & $t-B u$ & $\operatorname{Me}(\mathbf{1 e})$ & 3da & 69 \\
\hline 2 & $t-B u$ & Et (1/h) & 3ea & 85 \\
\hline 3 & $t$-Bu & $i-\operatorname{Pr}(\mathbf{1 i})$ & $3 f a$ & 57 \\
\hline 4 & $\mathrm{Bu}$ & $\operatorname{Me}(\mathbf{1} \mathbf{j})$ & 3ga & 50 \\
\hline 5 & $\mathrm{Ph}$ & $\operatorname{Me}(\mathbf{1 k})$ & 3ha & 31 \\
\hline 6 & $\mathrm{Me}_{3} \mathrm{Si}$ & $\operatorname{Me}(\mathbf{1 I})$ & 3ba & 60 \\
\hline 7 & $t$-Bu(Me $)_{2} \mathrm{Si}$ & $\operatorname{Me}(\mathbf{1} \mathbf{m})$ & 3ia & 89 \\
\hline
\end{tabular}


fect of a substituent on the aromatic ring of azobenzenes 2b-k on the chemical yield was notable: an electron-withdrawing group ( $\mathrm{Cl}$ or $\mathrm{F}$ ) at 4-position of the phenyl group enhanced the electrophilicity of $\mathbf{2 e}$ and $\mathbf{2 f}$ relative to $\mathbf{2 d}$, which has an electron-donating MeO group (entries 4 and 5 vs. entry 3). A methyl group at 2-position reduced the reactivity of $\mathbf{2 i}$ (entry 8 ), whereas 2-F substituted azobenzene showed significant reactivity probably due to its electronic effect rather than its steric hindrance (entry 9 ).

Table 3 Metallic-Barium-Promoted Barbier-Type Propargylation of Symmetrical Azobenzenes $\mathbf{2} \mathbf{b}-\mathbf{k}$ with Propargylic Tosylate $\mathbf{1} \mathbf{h}^{\mathrm{a}}$

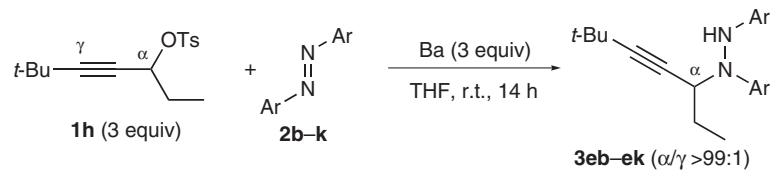

\begin{tabular}{cllc}
\hline Entry & Ar & Product & Yield (\%) \\
\hline $1^{c}$ & $4-\mathrm{MeC}_{6} \mathrm{H}_{4} \mathbf{2 b}$ & $\mathbf{3 e b}$ & 80 \\
2 & $4-i-\mathrm{PrC}_{6} \mathrm{H}_{4} \mathbf{2 c}$ & $\mathbf{3 e c}$ & 73 \\
3 & $4-\mathrm{MeOC}_{6} \mathrm{H}_{4} \mathbf{2 d}$ & $\mathbf{3 e d}$ & 27 \\
4 & $4-\mathrm{ClC}_{6} \mathrm{H}_{4} \mathbf{2 e}$ & $\mathbf{3 e e}$ & 56 \\
5 & $4-\mathrm{FC}_{6} \mathrm{H}_{4} \mathbf{2 f}$ & $\mathbf{3 e f}$ & 60 \\
$6^{d}$ & $3-\mathrm{MeC}_{6} \mathrm{H}_{4} \mathbf{2 g}$ & $\mathbf{3 e g}$ & 77 \\
7 & $3-\mathrm{ClC}_{6} \mathrm{H}_{4} \mathbf{2 h}$ & $\mathbf{3 e h}$ & 51 \\
8 & $2-\mathrm{MeC}_{6} \mathrm{H}_{4} \mathbf{2 i}$ & $\mathbf{3 e i}$ & 10 \\
$9^{d}$ & $2-\mathrm{FC}_{6} \mathrm{H}_{4} \mathbf{2 j}$ & 3ej & $>99$ \\
10 & $2,4-\mathrm{F}_{2} \mathrm{C}_{6} \mathrm{H}_{3} \mathbf{2 k}$ & 3ek & 51 \\
\hline
\end{tabular}

a The Barbier-type reaction was carried out using propargylic tosylate $\mathbf{1 h}$ (3 equiv), metallic barium ( 3 equiv), and azobenzenes $\mathbf{2} \mathbf{b}-\mathbf{k}$ (1 equiv) in THF at room temperature for $14 \mathrm{~h}$.

b The chemical yield was determined by ${ }^{1} \mathrm{H}$ NMR spectroscopy using 1,4 bis(trimethylsilyl)benzene as the internal standard.

c The reaction was performed for $15 \mathrm{~h}$.

d The reaction was performed for $8 \mathrm{~h}$.

To investigate the electronic effect on the site selectivity of the nitrogen atoms, we carried out the propargylation of unsymmetrical azobenzene derivatives having an electrondeficient group on one aromatic ring and/or an electronrich group on the other aromatic ring. As a result, a 44:56 mixture of two regioisomers $\mathbf{A}$ and $\mathbf{B}$ was obtained as product 3el + 3el' in the reaction of 1-(4-tolyl)-2-phenyldiazene (2l) with 6,6-dimethylhept-4-yn-3-yl 4-methylbenzenesulfonate (1h) almost quantitatively (Table 4, entry 1 ). In contrast, the reaction of unsymmetrical diaryl azo compounds $\mathbf{2 m}$ and $\mathbf{2 n}$, which have a 4-halophenyl group as the $\mathrm{Ar}^{2}$ group, resulted in the formation of regioisomer A selectively (entries 2 and 3). Similar site selectivities were observed in the cases of 1-(4-fluorophenyl)-2-(4-tolyl)diazene (2o) and 1-(4-fluorophenyl)-2-(4-isopropylphenyl)diazene (2p), but with unsatisfactory isolated yields (entries 4 and 5 ). The highest site selectivity was realized with a 2-tolyl group as the $\mathrm{Ar}^{1}$ group and a 2-fluorophenyl group as the $\mathrm{Ar}^{2}$ group (entry 6). A similar site selectivity was achieved by using 1 (2,4-difluorophenyl)-2-(3-tolyl)diazene (2r) as the substrate: a 64:36 mixture of propargylic hydrazines $\mathbf{A}$ and $\mathbf{B}$ was obtained in $40 \%$ combined yield (entry 7 ).

Table 4 Metallic-Barium-Promoted Barbier-Type Propargylation of Unsymmetrical Azobenzenes $\mathbf{2 l}-\mathbf{r}$ with Propargylic Tosylate $\mathbf{1 h}^{\mathbf{a}}$

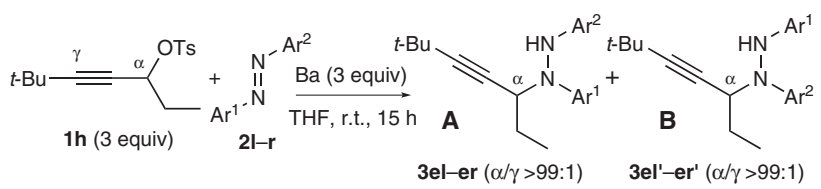

\begin{tabular}{|c|c|c|c|c|c|}
\hline Entry & $\mathrm{Ar}^{1}$ & $\mathrm{Ar}^{2}$ & Product & Yield (\%) & $A / B^{c}$ \\
\hline 1 & $\mathrm{Ph}$ & $4-\mathrm{MeC}_{6} \mathrm{H}_{4} 2 \mathrm{l}$ & $3 e l+3 e l^{\prime}$ & $>99$ & $44: 56$ \\
\hline 2 & $\mathrm{Ph}$ & $4-\mathrm{FC}_{6} \mathrm{H}_{4} 2 \mathrm{~m}$ & $3 e m+3 e m^{\prime}$ & 78 & $57: 43$ \\
\hline 3 & $\mathrm{Ph}$ & $4-\mathrm{ClC}_{6} \mathrm{H}_{4} \mathbf{2 n}$ & $3 e n+3 e n^{\prime}$ & 92 & $55: 45$ \\
\hline 4 & 4- $\mathrm{MeC}_{6} \mathrm{H}_{4}$ & $4-\mathrm{FC}_{6} \mathrm{H}_{4} 20$ & $3 e o+3 e o '$ & 57 & $58: 42$ \\
\hline 5 & 4-i- $\operatorname{PrC}_{6} \mathrm{H}_{4}$ & $4-\mathrm{FC}_{6} \mathrm{H}_{4} 2 \mathrm{p}$ & $3 e p+3 e p^{\prime}$ & 39 & $56: 44$ \\
\hline 6 & 2- $\mathrm{MeC}_{6} \mathrm{H}_{4}$ & $2-\mathrm{FC}_{6} \mathrm{H}_{4} \mathbf{2 q}$ & $3 e q+3 e q^{\prime}$ & $>99$ & $66: 34$ \\
\hline 7 & 3- $\mathrm{MeC}_{6} \mathrm{H}_{4}$ & $2,4-\mathrm{F}_{2} \mathrm{C}_{6} \mathrm{H}_{3} 2 \mathrm{r}$ & $3 e r+3 e r^{\prime}$ & 40 & $64: 36$ \\
\hline
\end{tabular}

${ }^{a}$ The Barbier-type reaction was carried out using propargylic tosylate $\mathbf{1 h}$ (3 equiv), metallic barium (3 equiv), and azobenzenes $2 \mathbf{l}-\mathbf{r}$ (1 equiv) in THF at room temperature for $15 \mathrm{~h}$.

${ }^{b}$ The chemical yield was determined by ${ }^{1} \mathrm{H}$ NMR spectroscopy using 1,4 bis(trimethylsilyl)benzene as the internal standard.

c The ratio was determined by ${ }^{1} \mathrm{H}$ NMR spectroscopy or ${ }^{19} \mathrm{~F}$ NMR spectroscopy. The structure of the major isomer was determined by $\mathrm{N}-\mathrm{N}$ bond cleavage.

The thus-obtained propargylic hydrazines can be further converted into propargylic amines through reductive $\mathrm{N}-\mathrm{N}$ bond cleavage. ${ }^{10}$ For example, treatment of propargylic hydrazine derivative 3da with an excess of $\mathrm{Zn}$ in acetic acid $^{11}$ at room temperature for $15 \mathrm{~h}$ afforded corresponding propargylic amine 4da in $32 \%$ yield (Table 5, entry 1 ). Elevating the reaction temperature was effective in acquiring a higher yield and when the reaction was performed at $80^{\circ} \mathrm{C}$, a satisfactory isolated yield of 4da was obtained (entry 3 ). Decreasing the amount of zinc (entry 4), shortening the reaction time (entry 5), diluting the reaction solution (entries 6 and 7), and employing trifluoroacetic acid instead of acetic acid (entry 8) did not improve the yield.

With the optimized reaction conditions in hand, we then executed the $\mathrm{N}-\mathrm{N}$ bond cleavage of diverse propargylic hydrazines employing $\mathrm{Zn}$ in AcOH. $\alpha$-Ethylated propargylic hydrazine 3ea showed higher reactivity than 3da (Table 6 , entry 1 vs. Table 5 , entry 3 ). Not only electron-rich hydrazines but also electron-deficient hydrazines provided the anticipated propargylic amines in satisfactory yields (Table 6, entries 2-5). Regioisomeric mixtures of 3eq and 3eq' effectively underwent the $\mathrm{N}-\mathrm{N}$ bond cleavage (Table 6 , entry 6) and as a result, regioisomer 3eq was unambiguously determined to be the major product of the reaction shown in Table 4, entry 6. Similarly, regioisomer 3er was 
Table 5 Optimization of Reductive N-N Bond Cleavage of Propargylic Hydrazine (3da)

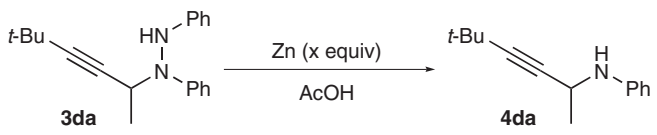

\begin{tabular}{lcccc}
\hline Entry & $\mathrm{x}$ & Temp $\left({ }^{\circ} \mathrm{C}\right)$ & Time $(\mathrm{h})$ & Yield $(\%)^{\mathrm{b}}$ \\
\hline 1 & 100 & r.t. & 15 & 32 \\
2 & 100 & 40 & 15 & 57 \\
3 & 100 & 80 & 15 & 80 \\
4 & 50 & 80 & 15 & 70 \\
5 & 100 & 80 & 4 & 78 \\
$6^{\mathrm{c}}$ & 100 & 80 & 4 & 46 \\
$7^{\mathrm{c}}$ & 100 & 120 & 4 & 68 \\
$8^{\mathrm{d}}$ & 100 & 80 & 4 & 33 \\
\hline
\end{tabular}

a The reaction was carried out using propargylic hydrazine 3 da (1 equiv) and zinc dust (x equiv) in acetic acid $(1.5 \mathrm{~mL})$ at the specified temperature for $4 \mathrm{~h}$ or $15 \mathrm{~h}$.

b Isolated yield.

c Acetic acid (3 mL) was used

d Trifluoroacetic acid was used in place of acetic acid.

found to be the major product in the reaction shown in Table 4 , entry 7 from the result of the reduction of a mixture of 3er and 3er' (Table 6, entry 7).

Subsequently, we investigated the benzidine rearrangement of propargylic hydrazine 3ea, which afforded corresponding biphenylamine 5ea through the $\mathrm{N}-\mathrm{N}$ bond cleavage of 3ea under acidic conditions. ${ }^{12}$ Optimization of the reaction temperature and the reaction time was performed, and the results are shown in Table 7. When 3ea was ex- posed to a 2:3 mixture of THF and $2 \mathrm{M} \mathrm{HCl}$ (aq) at $50{ }^{\circ} \mathrm{C}$ for $20 \mathrm{~h}$, anticipated biphenylamine 5 ea was obtained in $47 \%$ yield (Table 7 , entry 1 ). When the reaction temperature was elevated to $70{ }^{\circ} \mathrm{C}$, the yield was improved to $56 \%$ (entry 2 ). Attempts to carry out the rearrangement for a shorter reaction time and/or at a higher reaction temperature were not effective in gaining better results ( entries 3 and 4).

A substituent on the aromatic ring of propargylic hydrazines affected the isolated yields of the products. Introduction of a methyl group to 3-position decreased the yield of $5 \mathbf{d g}$ because of steric repulsion between the two methyl groups of product $\mathbf{5 d g}$ (Table 8, entry 2). 2-Methyl-substi-

Table 7 Optimization of Benzidine Rearrangement of Propargylic Hydrazine $3 \mathbf{e a}^{\mathrm{a}}$

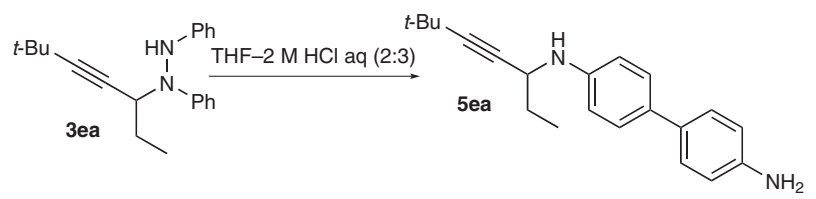

\begin{tabular}{lccc}
\hline Entry & $\left.\operatorname{Temp}^{\circ}{ }^{\circ} \mathrm{C}\right)$ & Time $^{(\mathrm{h})}$ & Yield $^{(\%)^{\mathrm{b}}}$ \\
\hline 1 & 50 & 20 & 47 \\
2 & 70 & 20 & 56 \\
3 & 70 & 7 & 51 \\
4 & 120 & 7 & 28 \\
\hline
\end{tabular}

a The reaction was carried out using propargylic hydrazine 3 ea in a mixture of THF $(1 \mathrm{~mL})$ and $2 \mathrm{M} \mathrm{HCl} \mathrm{aq}(1.5 \mathrm{~mL})$ at the specified temperature for $7 \mathrm{~h}$ or $20 \mathrm{~h}$.

${ }^{\mathrm{b}}$ Isolated yield.

Table 6 Reductive N-N Bond Cleavage of Various Propargylic Hydrazines 3ea, 3eb, 3ef, 3ej, 3eq+3eq', and 3er + 3er ${ }^{\text {a }}$

\begin{tabular}{|c|c|c|c|c|c|}
\hline \multirow[b]{2}{*}{ Entry } & \multirow[b]{2}{*}{$\mathrm{Ar}^{1}$} & \multirow{2}{*}{$\begin{array}{l}\begin{array}{l}\text { 3ea, 3eb, 3ef, 3ej, } \\
\text { 3eq+3eq', and 3er+3er' }\end{array} \\
\mathrm{Ar}^{2}\end{array}$} & \multicolumn{2}{|c|}{$\begin{array}{l}\text { 4ea, 4eb, 4ef, 4ej, } \\
4 \text { eq+4eq', and } 4 \text { er+4er' }\end{array}$} & \multirow[b]{2}{*}{ Yield $(\%)^{\mathrm{b}}$} \\
\hline & & & & Product & \\
\hline 1 & $\mathrm{Ph}$ & Ph 3ea & & 4ea & 82 \\
\hline $2^{c}$ & 4- $\mathrm{MeC}_{6} \mathrm{H}_{4}$ & 4- $\mathrm{MeC}_{6} \mathrm{H}_{4} 3 \mathrm{eb}$ & & $4 \mathrm{eb}$ & 66 \\
\hline 3 & 4- $\mathrm{MeC}_{6} \mathrm{H}_{4}$ & 4- $\mathrm{MeC}_{6} \mathrm{H}_{4} 3 \mathrm{eb}$ & & $4 \mathrm{eb}$ & 96 \\
\hline $4^{c}$ & 4- $-\mathrm{FC}_{6} \mathrm{H}_{4}$ & $4-\mathrm{FC}_{6} \mathrm{H}_{4} 3$ ef & & 4 ef & 55 \\
\hline 5 & $2-\mathrm{FC}_{6} \mathrm{H}_{4}$ & 2- $\mathrm{FC}_{6} \mathrm{H}_{4}$ 3ej & & 4ej & 75 \\
\hline $6^{d}$ & $2-\mathrm{MeC}_{6} \mathrm{H}_{4} / 2-\mathrm{FC}_{6} \mathrm{H}_{4}$ & $2-\mathrm{FC}_{6} \mathrm{H}_{4} 3 \mathbf{e q} / 2-\mathrm{MeC}_{6} \mathrm{H}_{4}$ & 3eq', 3eq + 3eq' (66:34) & $4 e q+4 e q^{\prime}$ & $82(74: 26)$ \\
\hline $7^{d}$ & 3- $-\mathrm{MeC}_{6} \mathrm{H}_{4} / 2,4-\mathrm{F}_{2} \mathrm{C}_{6} \mathrm{H}_{3}$ & $2,4-\mathrm{F}_{2} \mathrm{C}_{6} \mathrm{H}_{3} 3 \mathrm{er} / 3-\mathrm{MeC}_{6} \mathrm{H}$ & $\mathrm{H}_{4} 3 e r^{\prime}, 3 e r+3 e r^{\prime}(64: 36)$ & $4 e r+4 e r^{\prime}$ & $>99(69: 31)$ \\
\hline
\end{tabular}


tuted substrate 3di displayed comparable reactivity to 3da (entry 3 vs. entry 1). The existence of an electron-withdrawing group significantly decreased the yield of $\mathbf{5 d j}$ probably due to suppression of protonation of the two amino groups (entry 4 ).

Table 8 Benzidine Rearrangement of Various Propargylic Hydrazines 3da, 3dg, 3di, and 3dj

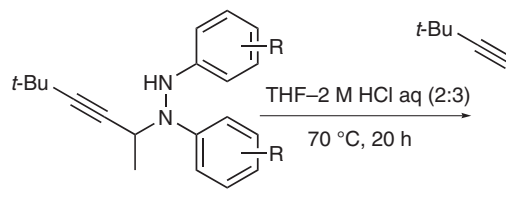

3da, 3dg, 3di, and 3dj

$5 \mathrm{da}, 5 \mathrm{dg}, 5 \mathrm{di}$, and $5 \mathrm{dj}$

\begin{tabular}{llll}
\hline Entry & R & Product & Yield (\%) \\
\hline 1 & H 3da & 5da & 56 \\
2 & 3-Me 3dg & $\mathbf{5 d g}$ & 30 \\
3 & 2-Me 3di & $\mathbf{5 d i}$ & 54 \\
4 & 2-F 3dj & $\mathbf{5 d j}$ & 9 \\
\hline
\end{tabular}

a The reaction was carried out using propargylic hydrazines $\mathbf{3 d a}, \mathbf{3 d g}, \mathbf{3 d i}$, and $3 \mathrm{dj}$ in a mixture of THF $(1 \mathrm{~mL})$ and $2 \mathrm{M} \mathrm{HCl} \mathrm{aq}(1.5 \mathrm{~mL})$ at $70^{\circ} \mathrm{C}$ for $20 \mathrm{~h}$. b Isolated yield.

A proposed reaction mechanism is illustrated in Scheme 2. Two pathways are possible for propargylic hydrazines $\mathbf{3}$ $(\alpha$-adducts). A barium reagent generated from propargylic tosylate 1-OTs and metallic barium is supposed to be present in equilibrium between propargylic isomer 6 and allenylic isomer $7 .{ }^{13}$ Thus, $\alpha$-adducts are accessible from both isomers $\mathbf{6}$ and $\mathbf{7}$ by treating them with azo compound $\mathbf{2}$ via transition-state models $\mathbf{8}$ and $\mathbf{9}$, respectively, although former structure $\mathbf{8}$ is more favorable due to minimal steric repulsion. Meanwhile, allenylic hydrazines ( $\gamma$-adducts) can be formed from 6 by an $\mathrm{S}_{\mathrm{E}} 2^{\prime}$-type reaction of $\mathbf{6}$ with azo compound 2 through six-membered cyclic transition state $\mathbf{1 0}$. However, $\mathbf{1 0}$ is unstable due to steric repulsion between the $\mathrm{R}^{1}$ group of the barium reagent and an aryl group of the azo compound. As a consequence, propargylic barium species 6 is anticipated to react preferentially at the $\alpha$-carbon with azo compound $\mathbf{2}$ via four-membered cyclic transition state $\mathbf{8},{ }^{14}$ yielding the $\alpha$-adduct selectively. Furthermore, in the case of unsymmetrical azobenzene $\left(\mathrm{Ar}^{1}=\right.$ electron-rich $\mathrm{Ar}$ group; $\mathrm{Ar}^{2}=$ electron-deficient Ar group), the propargylation occurs selectively at the nitrogen atom which bonds to $\mathrm{Ar}^{1}$ group, because the nitrogen atom is considered to be relatively electron-deficient probably due to resonance effect. In contrast, another relatively electron-rich nitrogen atom is allowed to coordinate to barium atom.

In conclusion, we have achieved a novel Barbier-type propargylation of azo compounds with barium reagents that are prepared from propargylic tosylates and metallic barium. The employment of metallic barium as the source of barium reagents has enabled the synthesis of various

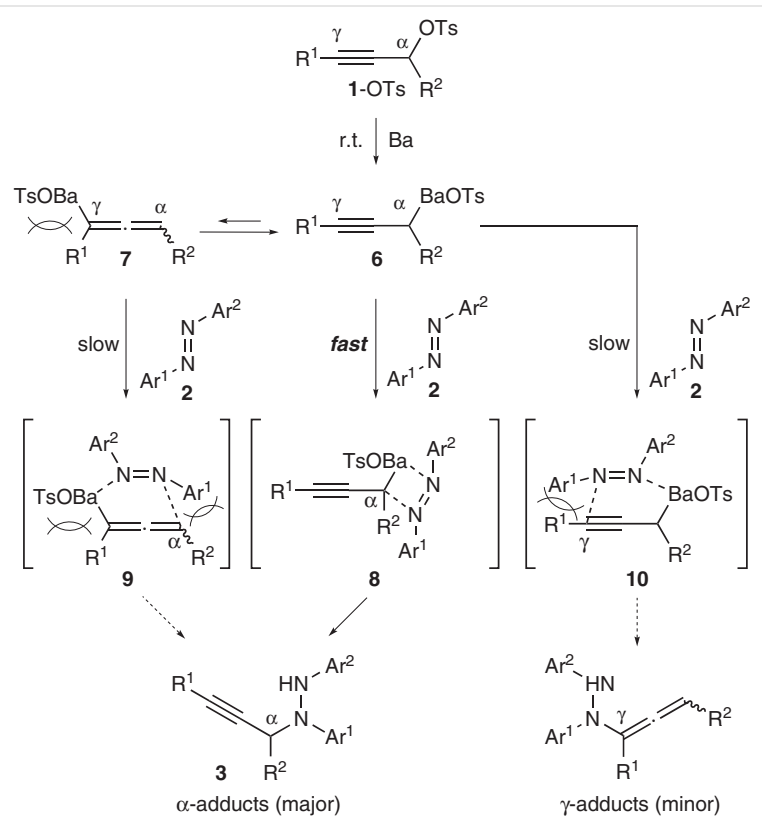

Scheme 2 Proposed reaction pathways to $\alpha$-adducts and $\gamma$-adducts

propargylic hydrazines in a regioselective manner. ${ }^{15}$ In addition, the site-selective propargylation of unsymmetrical azo compounds has been realized, giving isomeric ratios of up to $66: 34$. The utility of the propargylated product has been further demonstrated by their transformation into propargylated amines and propargylated biphenylamines through two types of $\mathrm{N}-\mathrm{N}$ bond cleavage. Further studies of related reactions promoted by metallic barium are under way.

\section{Acknowledgement}

We gratefully acknowledge financial support from Nippoh Chemicals Co., Ltd.

\section{Supporting Information}

Supporting information for this article is available online at https://doi.org/10.1055/s-0040-1706414.

\section{References and Notes}

(1) (a) Sell, M. S.; Rieke, R. D. Synth. Commun. 1995, 25, 4107. For reviews, see: (b) Rieke, R. D.; Sell, M. S.; Klein, W. R.; Chen, T.-A.; Brown, J. D.; Hanson, M. V. In Active Metals. Preparation, Characterization, Applications; Fürstner, A., Ed.; VCH: Weinheim, 1996, 1. (c) Rieke, R. D.; Hanson, M. V. Tetrahedron 1997, 53, 1925.

(2) (a) Yanagisawa, A.; Okitsu, S.; Arai, T. Synlett 2005, 1679. (b) Yanagisawa, A.; Suzuki, T.; Koide, T.; Okitsu, S.; Arai, T. Chem. Asian J. 2008, 3, 1793.

(3) Yanagisawa, A.; Koide, T.; Yoshida, K. Synlett 2010, 1515.

(4) Yanagisawa, A.; Jitsukawa, T.; Yoshida, K. Synlett 2013, 24, 635. 
(5) Yanagisawa, A.; Sawae, T.; Yamafuji, S.; Heima, T.; Yoshida, K. Synlett 2015, 26, 1073.

(6) (a) Ma, G.; Xu, Z.; Zhang, P.; Liu, J.; Hao, X.; Ouyang, J.; Liang, P.; You, S.; Jia, X. Org. Process Res. Dev. 2014, 18, 1169. (b) Fonseca, T. S.; da Silva, M. R.; de Oliveira, M. C. F.; de Lemos, T. L. G.; Marques, R. A.; de Mattos, M. C. Appl. Catal., A 2015, 492, 76.

(7) (a) Fowler, J. S. J. Org. Chem. 1977, 42, 2637. (b) Divya, K.; Narayana, B. ISRN Spectrosc. 2014, 541970/1.

(8) Yanagisawa, A.; Yamafuji, S.; Sawae, T. Synlett 2016, 27, 2019.

(9) Prof. Miyoshi and co-workers have reported various reactions promoted by metallic strontium, see: (a) Miyoshi, N. In Science of Synthesis, Vol. 7; Yamamoto, H., Ed.; Thieme: Stuttgart, 2004, 685. (b) Miyoshi, N.; Ikehara, D.; Matsuo, T.; Kohno, T.; Matsui, A.; Wada, M. J. Synth. Org. Chem., Jpn. 2006, 64, 845. (c) Miyoshi, N.; Matsuo, T.; Kikuchi, M.; Wada, M. J. Synth. Org. Chem., Jpn. 2009, 67, 1274. (d) Miyoshi, N.; Kohno, T.; Wada, M.; Matsunaga, S.; Mizota, I.; Shimizu, M. Chem. Lett. 2009, 38, 984. (e) Miyoshi, N.; Matsuo, T.; Mori, M.; Matsui, A.; Kikuchi, M.; Wada, M.; Hayashi, M. Chem. Lett. 2009, 38, 996. (f) Miyoshi, N.; Asaoka, M.; Miyazaki, Y.; Tajima, T.; Kikuchi, M.; Wada, M. Chem. Lett. 2012, 41, 35.

(10) For a review of reductive $\mathrm{N}-\mathrm{N}$ bond cleavage of hydrazines, see: Gilchrist, T. L. In Comprehensive Organic Synthesis, Vol. 8; Trost, B. M.; Fleming, I., Ed.; Pergamon Press: Oxford, 1991, 388.

(11) Sapountzis, I.; Knochel, P. Angew. Chem. Int. Ed. 2004, 43, 897.

(12) Bunton, C. A.; Rubin, R. J. J. Am. Chem. Soc. 1976, 98, 4236.

(13) For reviews, see: (a) Epsztein, R. In Comprehensive Carbanion Chemistry, Chap. 3; Buncel, E.; Durst, T., Ed.; Elsevier: New York, 1984, 107. (b) Yamamoto, H. In Comprehensive Organic Synthesis, Vol. 2; Trost, B. M.; Fleming, I.; Heathcock, C. H., Ed.; Pergamon Press: Oxford, 1991, 81.
(14) Exactly what causes propargylic barium reagent 6 to react selectively at the $\alpha$-carbon with azo compound 2 is not clear; however, the unusually long barium-carbon bond $(2.76-2.88 \AA)$ might prevent the formation of a six-membered cyclic transition-state model 10 leading to the $\gamma$-adduct, see: Kaupp, M.; Schleyer, P. v. R. J. Am. Chem. Soc. 1992, 114, 491.

(15) Typical Experimental Procedure for the Barbier-Type Selective Propargylation of Diaryl Azo Compounds: Synthesis of 1-(6,6-Dimethylhept-4-yn-3-yl)-1,2-diphenylhydrazine (3ea, Table 2, Entry 2)

Freshly cut barium (small pieces, $103.0 \mathrm{mg}, 0.75 \mathrm{mmol}$ ), propargylic tosylate $\mathbf{1 h}(220.8 \mathrm{mg}, 0.75 \mathrm{mmol})$, and azobenzene (45.6 $\mathrm{mg}, 0.25 \mathrm{mmol}$ ) were placed in a Schlenk tube $(25 \mathrm{~mL})$ under an argon atmosphere and covered with dry THF $(1 \mathrm{~mL})$. The mixture was stirred for $14 \mathrm{~h}$ at room temperature. The mixture was treated with sat. aq $\mathrm{NH}_{4} \mathrm{Cl}(10 \mathrm{~mL})$, and the aqueous layer was extracted three times with $\mathrm{Et}_{2} \mathrm{O}(10 \mathrm{~mL}$ each). The combined organic extracts were washed with brine, dried over $\mathrm{Na}_{2} \mathrm{SO}_{4}$, and concentrated in vacuo after filtration. The residual crude product was purified by column chromatography on silica gel (hexane-MeOH, 50:1) to afford propargylic hydrazine 3ea (65.5 mg, 85\% yield).

${ }^{1} \mathrm{H}$ NMR $\left(400 \mathrm{MHz}, \mathrm{CDCl}_{3}\right): \delta=7.25-7.15(\mathrm{~m}, 4 \mathrm{H}, \mathrm{Ar}-\mathrm{H}), 7.05-$ $7.03(\mathrm{~d}, 2 \mathrm{H}, J=8.2 \mathrm{~Hz}, \mathrm{Ar}-\mathrm{H}), 6.91-6.85(\mathrm{~m}, 3 \mathrm{H}, \mathrm{Ar}-\mathrm{H}), 6.77-$ $6.74(\mathrm{t}, 1 \mathrm{H}, J=7.3 \mathrm{~Hz}, \mathrm{Ar}-\mathrm{H}), 5.67$ (br, $1 \mathrm{H}, \mathrm{NH}), 4.43-4.39$ (t, 1 $\mathrm{H}, J=7.5 \mathrm{~Hz}, \mathrm{CH}), 1.89-1.66\left(\mathrm{~m}, 2 \mathrm{H}, \mathrm{CH}_{2}\right), 1.16\left(\mathrm{~s}, 9 \mathrm{H}, 3 \mathrm{CH}_{3}\right)$, 1.04-1.00 (t, $\left.3 \mathrm{H}, J=7.4 \mathrm{~Hz}, \mathrm{CH}_{3}\right) .{ }^{13} \mathrm{C}$ NMR $\left(99.5 \mathrm{MHz}, \mathrm{CDCl}_{3}\right)$ : $\delta=150.8,149.0,129.1,128.9,120.7,118.9,116.2,112.1,94.9$, 75.1, 58.1, 31.4, 31.1, 27.4, 11.4. IR (neat): 3311, 2965, 2359, 1600, 1496, 1362, 1308, 1239, 1170, 1092, 1025, 992, 857, 819, $745,691,628 \mathrm{~cm}^{-1}$. MS (ESI): $m / z$ calcd for $\left[\mathrm{C}_{21} \mathrm{H}_{27} \mathrm{~N}_{2}\right]^{+}[\mathrm{M}+\mathrm{H}]^{+}$: 307.2169; found: 307.2170 ; $\mathrm{mp} 57-60{ }^{\circ} \mathrm{C}$. 